\title{
Mestrado profissional: desenvolvimento pessoal e profissional
}

\author{
Professional masters: personal and social \\ development
}

\section{Maestría profesional: desarrollo personal y profesional}

Rosali Gomes Araújo Maciel, mestre em Gestão e Estratégia em Negócios pela Universidade Federal Rural do Rio de Janeiro e docente e coordenadora de Ensino de Graduação do Centro Universitário de Barra Mansa (UBM). Endereço: Centro Universitário de Barra Mansa, Rua 35, n 714, Fazenda Santa Cecília. CEP: 99999-999 - Barra Mansa, RJ. Telefone: (24) 21020222. Ramal: 242. E-mail: rosaligam@yahoo.com.br.

Heloisa Guimarães Peixoto Nogueira, doutora em Letras pela Pontifícia Universidade Católica do Rio de Janeiro, mestre em Memória Social pela Universidade Federal do Estado do Rio de Janeiro (Unirio) e coordenadora e docente do Programa de Mestrado Profissional em Gestão e Estratégia em Negócios da Universidade Federal Rural do Rio de Janeiro (UFRRJ). Endereço: Universidade Federal Rural do Rio de Janeiro, Instituto de Ciências Humanas e Sociais, BR 465, Km 7 - Centro. CEP: 23890-000 Seropedica, RJ. Telefone: (21) 2681-4850. Fax: (21) 2682-1701. E-mail hpgn@terra.com.br.

\section{Resumo}

Regulamentado pela Portaria $n^{\circ} 80 / 1998$, nasce oficialmente no Brasil o mestrado profissional. Ao acrescentar ao mestrado a possibilidade de formação profissional como mais uma iniciativa para favorecer o ajuste social que o País precisa realizar, um campo fértil de pesquisa se abre. E é nesse espaço que se justifica a relevância deste estudo, que apresenta os ganhos sociais alcançados pelos alunos do 
Mestrado Profissional em Gestão e Estratégia em Negócios (PPGEN) da UFRRJ, matriculados nas turmas de 2005 e 2006. Por meio da adoção de metodologia qualitativa, são identificados os ganhos sociais que os alunos alcançaram.

Palavras-chave: Competências. Mestrado Profissional. Psicologia nas Organizações. Ganho Social.

\section{Abstract}

Regulated by Directive 80/1998, the Professional Masters was created in Brazil. By adding to the master's degree the possibility of professional formation as an initiative favoring the social adjustment that the country needs to make, a fertile field of research is opened. It is within this context that the relevancy of this study is justified. It has the objective of analyzing the social gains achieved by the students of the Professional Masters (PPGEN/UFRRJ) enrolled in the graduating classes of 2005 and 2006. Through the adoption of a qualitative research methodology, the social gains achieved by the enrolled students are identified.

Keywords: Competency. Professional Masters. Psychology of Organizations. Social Gain.

\section{Resumen}

Reglamentada por la Resolución nº 80/1998, nace oficialmente en Brasil la maestría profesional. Al sumar a la maestría la posibilidad de formación profesional como una iniciativa a más para favorecer el ajuste social que el País necesita realizar, se abre un campo fértil de investigación. Y es en este espacio que se justifica la relevancia de este estudio, que presenta los logros sociales alcanzados por los alumnos de la Maestría Profesional en Gestión y Estrategia en Negocios (PPGEN) de la UFRRJ (Universidad Federal Rural de Río de Janeiro), inscriptos en 2005 y 2006. Por medio de la adopción de la metodología cualitativa, se identifican los logros sociales alcanzados por los alumnos.

Palabras clave: Competencias. Maestría Profesional. Psicología en las Organizaciones. Logro Social. 


\section{Introdução}

O presente trabalho tem como objetivo relatar a experiência de um grupo de egressos de um programa de mestrado profissional, apontando as dificuldades e os ganhos percebidos pelos alunos.

Faria sentido discorrer sobre os mestrados profissionais após mais de uma década de sua criação? Os achados desta pesquisa apontam que sim. Eles pretendem ser mais uma contribuição para a consolidação desse modelo de programa de pós-graduação stricto sensu, que aspira estimular a formação de mestres profissionais habilitados para desenvolver atividades de trabalho técnico-científico, com competências para agregar competitividade e aumentar a produtividade das empresas onde atuam.

Estudos que apontam os significados que os egressos de programas de mestrado profissional atribuem à sua experiência durante e após a conclusão do curso permitem conhecer o resultado da formação, os ganhos e os desafios que enfrentam, oferecendo um rico material às instituições proponentes. Representam outro olhar avaliativo, complementar ao do de indicadores estabelecidos pela Capes. Ao comparar os objetivos da oferta com a experiência dos egressos, é possivel avaliar se o projeto atingiu seus propósitos, se capacitou seus alunos para uma prática profissional avançada e transformadora.

Sob esse ângulo, faz sentido conhecer experiências de outras IES. Elas oferecem a possibilidade de um novo olhar e de novas reflexões.

Apoiando-se nessas ponderações, este trabalho apresenta os resultados de uma avaliação qualitativa, realizada durante o ano de 2008, junto a um grupo de alunos matriculados no Mestrado Profissional em Gestão e Estratégia em Negócios (PPGEN) da Universidade Federal Rural do Rio de Janeiro (UFRRJ), turmas de 2005 e 2006.

O curso de pós-graduação stricto sensuem Gestão e Estratégia em Negócios oferecido pela UFRRJ foi criado em 2000. Na ocasião, contava com uma estrutura curricular organizada em disciplinas 
obrigatórias, básicas e optativas, assim distribuídas: 14 créditos obrigatórios, 12 optativos e oito destinados à elaboração e defesa de projeto, além das exigências de publicar dois artigos em revistas indexadas ou eventos Qualis e de participar em seminários realizados no âmbito da instituição. A organização curricular foi concebida de modo a permitir um percurso crescente e gradativo dos saberes de gestão e estratégia (VILLAS BOAS et al., 2006).

No quadro dos créditos obrigatórios, foram elencadas as seguintes disciplinas: Comportamento Organizacional, Negociação e Processo Decisório, Administração Estratégica da Informação, Pesquisa Científica em Administração, Estratégia Empresarial Avançada e Gestão para Excelência. Nos dos créditos básicos: Marketing Estratégico, Gestão Estratégica com Pessoas, Medida em Ciências Sociais e do Comportamento, Gerência de Operações. Finalmente, no quadro dos créditos optativos: Orientação e Elaboração de Dissertação, Didática do Ensino de Administração, Quantitativo em Administração, Comércio Eletrônico, Novos Paradigmas Organizacionais e Sociedade, Empreendedorismo e Negócios, Desenvolvimento Local e Global, Competitividade em Cadeias Agroindustriais e Gestão de Empresas Agroindustriais.

Os resultados da pesquisa assinalam a abrangência do conhecimento nos âmbitos profissional, pessoal e social dos egressos.

Os dados foram obtidos a partir de entrevista semiestruturada, tratados segundo a técnica de análise de conteúdo proposta por Bardin (1995) e analisados à luz do referencial teórico de Sarsur (2007), Zarifian (2001) e Boterf (2003).

\section{Os mestrados profissionais}

Os mestrados profissionais surgem no Brasil em um momento em que o País e outras nações avaliam os rumos que a educação deve seguir. Embora concebidos no documento que lançou as bases da pósgraduação no Brasil, somente em 1995 essa modalidade passou a ser 
praticada e reconhecida, gerando discussões dentro e fora da academia acerca da validade de sua titulação, da sua estrutura curricular, dentre outros aspectos.

Em dezembro de 1991, o diretor-geral da UNESCO convocou uma comissão internacional com a missão de efetuar um trabalho de estudo e reflexão sobre os desafios que a educação deverá enfrentar nos próximos anos, apresentando sugestões e recomendações (DELORS et al., 1996).

Ocaráterestratégicodaformação de mãodeobraeanecessidade da mobilização dos setores envolvidos, entre eles, as instituições de ensino, de modo a fornecerem respostas às necessidades do tempo em que se vive e, sobretudo, à formação profissional necessária, passam a ser pontuados.

[...] Já não é mais possível pedir aos sistemas educativos que formem mão-de-obra para empregos industriais estáveis. Trata-se, antes, de formar para a inovação pessoas capazes de evoluir, de se adaptar a um mundo em rápida mudança e capazes de dominar essas transformações [...] (DELORS et al., 1996, p. 72).

Foi nesse período que o ensino superior brasileiro passou por intensas reformas e transformações, especialmente a pós-graduação stricto sensu, que se viu impelida a buscar um lócus diferenciado das tradicionais academias, a adotar o ensino a distância e a implantar os mestrados profissionais (MELO; OLIVEIRA, 2005).

Em 1995, ocorreu a revisão do modelo praticado, em função da necessidade de flexibilização do modelo de pós-graduação stricto sensu, em particular o nível de mestrado, tendo em vista:

[...] as profundas transformações econômico-sociais experimentadas pela sociedade brasileira nas últimas décadas, processo esse que tem implicado sensivel expansão e diferenciação do sistema produtivo e da estrutura de empregos, têm também acarretado o surgimento de novas demandas de formação de profissionais de alto nível que não irão, necessariamente, atuar na vida acadêmica [...] (NEVES, 1995 apud BARROS et al., 2005, p. 125). 
Ainda em 1995, é constituída uma comissão que elaborou o documento "Mestrado no Brasil - A Situação e uma Nova Perspectiva", que deu origem à proposta do Programa de Flexibilização do Modelo de Pós-Graduação stricto sensu. Nesse documento, elaborado pela diretoria da Capes, são apresentados os requisitos que as instituições proponentes de cursos devem possuir, de modo a assegurar a qualidade do sistema de pós-graduação. Esse trabalho foi aprovado pelo Conselho, resultando na Resolução $n^{\circ}$ 01/95, publicada por meio da Portaria $n^{\circ}$ 47/95, que determina a implantação na Capes de procedimentos apropriados à recomendação, ao acompanhamento e à avaliação de cursos de mestrado dirigidos à formação profissional, estabelecendo os requisitos e as condicionantes (BARROS et al., 2005).

Em 1998, a Portaria n 80/1998 (BRASIL, 1998) revoga a Portaria $n^{\circ} 47$, esclarecendo e norteando os requisitos e as condições para 0 enquadramento das propostas de mestrado profissional, dispondo sobre o reconhecimento dos mestrados profissionalizantes no Brasil.

Regulamentado pela Portaria n 80/1998, nasce oficialmente o mestrado profissional. Em suas prioridades, está o compromisso de agregar competitividade e produtividade às empresas e melhorar a gestão dos setores sociais do governo e demais organizações, acrescentando qualidade na produção de bens e serviços (RIBEIRO, 2005). Enfatiza os problemas externos à academia e a qualidade avaliada e testada pela Capes, vistos como uma larga ponte de mão dupla que irá permitir o caminho entre a academia e a sociedade (SILVEIRA; SOUZA PINTO, 2005).

Dando sequência à sua regulamentação, surgem portarias e resoluçõesquetentamestabelecerasdiferençasentrecursosacadêmicos e profissionais. Segundo Ficher (2005), o mestrado profissional é um mestrado stricto sensu que obedece aos procedimentos típicos dessa modalidade de ensino, visando a horizontalidade e verticalidade do conhecimento. Visto como importante na integração e complementação entre os problemas profissionais e o conhecimento gerado na universidade, o mestrado profissional constitui oportunidade de maior aproximação entre os trabalhos conduzidos pela universidade e as demandas provenientes do campo social e profissional, além das demandas por soluções tecnológicas (QUELHAS, 2005). 
A diferença entre os dois tipos de mestrado, acadêmico e profissional, está no resultado produzido. Enquanto o primeiro pretende formar um pesquisador, cujo objetivo é a realização de estudos avançados em uma disciplina específica, sem ter o compromisso com suas aplicações, o segundo visa à formação para o mundo profissional, a partir da imersão na pesquisa aplicada, proporcionando formação científica e profissional de modo a consolidar conhecimentos capazes de tornar o profissional criativo, apto a adotar novas técnicas e processo, com vistas à expansão da indústria brasileira e às demandas de desenvolvimento de todos os segmentos nacionais (FICHER, 2005; LOPES NETO et al., 2005; APCN, 2005).

Em dezembro de 2009, uma nova portaria passa a vigorar, a Portaria Normativa $n^{\circ} 17$ (BRASIL, 2009), substituindo a Portaria $n^{\circ}$ 7 de 22 de junho de 2009. Com nova redação e pequenas alterações em relação ao disposto na Portaria $n^{\circ} 7$, esse novo documento dispõe sobre o mestrado profissional, considerando a necessidade de estimular a formação de mestres profissionais, definindo os objetivos do mestrado profissional e explicitando o que essa modalidade de formação possibilita:

I a capacitação de pessoal para a prática profissional avançada e transformadora de procedimentos e processos aplicados, por meio da incorporação do método científico, habilitando o profissional para atuar em atividades técnico-científicas e de inovação;

Il a formação de profissionais qualificados pela apropriação e aplicação do conhecimento embasado no rigor metodológico e nos fundamentos científicos; e

III a incorporação e atualização permanentes dos avanços da ciência e das tecnologias, bem como a capacitação para aplicar esses avanços, tendo como foco a gestão, a produção técnico-científica na pesquisa aplicada e a proposição de inovações e aperfeiçoamentos tecnológicos para a solução de problemas específicos.

Embora o mestrado profissional tenha sido idealizado no documento que criou a pós-graduação brasileira, o Parecer n ${ }^{\circ}$ 977/1965 (BRASIL, 1965), a tradição brasileira adotou o modelo acadêmico, o que responde pelo primeiro degrau para a formação acadêmica científica, 
necessária à carreira universitária (LOPES NETO et al., 2005). Foram necessárias três décadas para que a universidade rompesse com a visão de que os mestrados deveriam ser somente os acadêmicos.

Ao abrir um espaço de formação que permite o diálogo entre as universidades e os setores produtivos, a Coordenação de Aperfeiçoamento de Pessoal de Nivel Superior (Capes) ampliou a possibilidade de aperfeiçoamento do Sistema Nacional de PósGraduação, criando solo fértil para investigações acerca de como os mestrados profissionais estão se consolidando e, sobretudo, quais os resultados que estão produzindo.

\section{Competências}

As discussões acadêmicas sobre práticas de gestão e as mudanças na organização do trabalho têm estimulado as organizações a repensar suas estratégias de gestão de pessoas, visando a promoção do desenvolvimento pessoal de todos os trabalhadores e o preenchimento dos vazios deixados pelo método taylorista de gestão (CAMPOS, 1998).

Segundo Campos (1998), a racionalidade gerencial hegemônica, ancorada na lógica da administração científica proposta por Taylor, produziu e ainda produz sistemas de gestão de pessoas calcados na disciplina e no controle, exigindo que os trabalhadores abdiquem de seus interesses e desejos em prol das normas e do objeto do trabalho alheio.

Para reverter essa lógica e atender a demanda de profissionais com capacidade de trabalhar em equipe, compor consensos e alianças, implementar projetos, tomar iniciativa e se responsabilizar pelo que faz, colocando a inteligência prática nas situações, se apoiando nos conhecimentos adquiridos, transformando-os (ZARIFIAN, 2001; CAMPOS, 1998), Zarifian (2001) propõe a adoção da lógica do desenvolvimento de competências.

O conceito de competência adotado neste trabalho resulta da combinação dos propostos por Bitencourt,Zarifian e Boterf:competência 
é um processo contínuo e articulado de formação e desenvolvimento de conhecimentos, habilidades e atitudes, a partir da interação com outras pessoas (BITENCOURT, 2001), que possibilita ao indivíduo saber agir e reagir com pertinência, saber combinar recursos e mobilizálos em um contexto, saber transpor, saber determinar e interpretar indicadores de contexto, saber criar as condições de transponibilidade com o auxílio de esquemas transferíveis, saber aprender e aprender a aprender, saber envolver-se, saber assumir riscos e saber empreender e ter ética profissional (BOTERF, 2003). A competência se materializa na maneira como o indivíduo enfrenta as situações do trabalho, por isso, envolve o desejo do indivíduo de colocar seus saberes em prática, no ato de iniciar e assumir responsabilidades diante das situações com as quais depara (ZARIFIAN, 2001).

O que está em jogo não é mais disciplinar e controlar, mas co-responsabilizar e partilhar as experiências e decisões (ZARIFIAN, 2001; CAMPOS, 1998). Isso implica mudar da lógica da administração científica para a da competência, com sérias e consequentes mudanças no âmbito das instituições de ensino.

Considerando que o mestrado profissional é uma experiência de inovação e reinvenção em que alunos vêm iluminar as suas práticas com as teorias, as instituições proponentes dessa modalidade de ensino aprendem muito, tendo praticantes como alunos (MOURA CASTRO, 2005). Portanto, a formação dos alunos inscritos nessa modalidade de ensino deve se pautar pela adoção de metodologias que privilegiem o desenvolvimento de competências, visto que uma das características do profissional do novo milênio consiste em saber mobilizar e combinar, de modo pertinente, um conjunto de recursos para administrar uma situação complexa (BOTERF, 2003).

\section{Material e métodos}

Optou-se pela adoção do método qualitativo como caminho metodológico para identificar as percepções dos alunos sobre sua experiência e vivência no Programa de Mestrado Profissional em Gestão e Estratégia em Negócios. A esse olhar metodológico aliou-se a pesquisa bibliográfica, descritiva e de opinião. As pesquisas bibliográfica 
e documental foram realizadas em fontes primárias, livros e revistas que fundamentam o tema, além de sítios na internet, conforme as referências bibliográficas apresentadas ao final deste artigo.

A pesquisa envolveu um grupo de alunos de duas turmas do programa nos anos de 2005 e 2006, após a aprovação da Comissão de Ética em Pesquisa Experimental, protocolo nº 163/2008.

A amostra foi composta por oito homens e quatro mulheres, $27,9 \%$ do universo pesquisado, respeitando os critérios de seleção da amostra por variedade de tipos e o da exaustividade dos temas (TURATO, 2003). A idade dos atores pesquisados variou de 24 a 61 anos de idade, sendo que a maior concentração ficou entre 43 e 53 anos de idade.

A seguir, o Quadro 1 apresenta os critérios da amostragem.

\section{Quadro 1. Critérios da amostragem}

\begin{tabular}{l|l}
\hline Amostra por variedade de tipos & Critérios \\
\hline Por sexo & Masculino/ Feminino \\
\hline Por profissão & Docentes / Não-docentes e misto \\
\hline Por turmas & Turma 1 e Turma 2 \\
\hline
\end{tabular}

A definição da quantidade de elementos da amostra seguiu o critério da saturação, ou seja, quando os conteúdos começaram a se repetir, sem que houvesse acréscimos significativos aos objetivos desta pesquisa, foi feito o corte nas entrevistas.

Portanto, a escolha dos sujeitos respeitou os critérios da amostragem de tipos e o da amostragem proposital, intencional ou deliberada. Os sujeitos foram escolhidos a partir da disponibilidade para participar da entrevista e das contribuições que fariam aos pressupostos do trabalho. Tais condições se respaldam nos critérios de homogeneidade necessária que visa a assegurar características comuns entre os elementos da amostra e em tipos diversificados, de modo a capturar as eventuais semelhanças e diferenças entre os sujeitos (TURATO, 2003). 
Considerando que o tamanho da amostra pode variar de seis a 15 entrevistados, o número final de entrevista, após a saturação, foi de 12 entrevistados.

Os resultados e os dados obtidos a partir das entrevistas foram tratados segundo a técnica da análise de conteúdo proposta por Bardin, na sequência proposta: pré-análise, exploração do material e tratamento dos resultados, além de inferência e interpretação (BARDIN, 1995).

\section{Resultados e discussão}

Segundo Tillich (1972), nossas crenças direcionam nossas escolhas. Por essa razão, a questão 1, "O que te levou a buscar 0 Mestrado Profissional em Gestão e Estratégia em Negócios?”, objetivou identificar os tipos de crenças que motivaram a decisão de buscar um mestrado profissional.

\section{Motivos para fazer o mestrado profissional}

Foram encontradas 32 categorias ou unidades de análise, segundo o critério de repetição e de diferenciação. Após a codificação, tais categorias foram reduzidas a um conjunto de quatro categorias mais amplas, conforme descrito na Tabela 1.

Tabela 1. Categorização das respostas dos participantes à questão 1

\begin{tabular}{l|c|c}
\hline Categorias & Frequência & Porcentagem \\
\hline Conhecimento & 14 & $44 \%$ \\
\hline Titulação & 8 & $25 \%$ \\
\hline Oportunidade de cursar & 7 & $22 \%$ \\
\hline Empregabilidade & 3 & $9 \%$ \\
\hline Total & $\mathbf{3 2}$ & $\mathbf{1 0 0} \%$ \\
\hline
\end{tabular}

Os resultados apontam a busca de conhecimento como sendo o principal motivo que impulsionou esses profissionais a buscarem o Mestrado Profissional em Gestão e Estratégia em Negócios. Esse fato sugere que essas pessoas procuraram o mestrado profissional 
buscando satisfazer a necessidade de desenvolvimento profissional e a permanência no mercado de trabalho.

\section{A avaliação da experiência no mestrado profissional}

A análise da questão 2, fale-me de sua experiência no Mestrado Profissional, como o avalia?, produziu 75 categorias, que foram reduzidas a um conjunto de quatro categorias mais amplas, a partir dos critérios de repetição e de diferenciação, conforme descrito na Tabela 2 .

Tabela 2. Categorização das respostas dos participantes à questão 2

\begin{tabular}{l|l|l}
\hline Categorias & Frequência & Porcentagem \\
\hline Resultados produzidos & 32 & $42 \%$ \\
\hline Aspecto didático-pedagógico & 19 & $26 \%$ \\
\hline Restrições/dificuldades & 13 & $18 \%$ \\
\hline Sentimentos despertados & 10 & $14 \%$ \\
\hline
\end{tabular}

A Tabela 3 apresenta o resumo geral da categorização das respostas a partir das categorias e das unidades de análise, após a fusão das unidades de análise comuns em categorias mais amplas.

Tabela 3. Resumo geral da categorização das respostas dos participantes à questão 2

\begin{tabular}{|c|c|}
\hline $\begin{array}{l}\text { Resultados } \\
\text { produzidos }\end{array}$ & $\begin{array}{l}\text { - conhecimentos adquiridos; } \\
\text { - aplicação dos conhecimentos no campo profissional; } \\
\text { - melhoria no exercício profissional; e } \\
\text { - crescimento pessoal decorrente do convívio com } \\
\text { colegas e professores. }\end{array}$ \\
\hline $\begin{array}{l}\text { Aspecto didático- } \\
\text { pedagógico }\end{array}$ & $\begin{array}{l}\text { - } \text { metodologia; } \\
\text { - critérios avaliativos; e } \\
\text { - contribuições das disciplinas. }\end{array}$ \\
\hline $\begin{array}{l}\text { Restrições/ } \\
\text { dificuldades }\end{array}$ & $\begin{array}{l}\text { - organização curricular; } \\
\text { - volume de atividades; e } \\
\text { - prazo para cumprimento das tarefas. }\end{array}$ \\
\hline $\begin{array}{l}\text { Sentimentos } \\
\text { despertados }\end{array}$ & - sentimento de bem-estar produzido. \\
\hline
\end{tabular}

Segundo Zarifian (2001), um dos principais efeitos esperados do desenvolvimento de competências é o de produzir melhoria na 
organização do trabalho. Quarenta e dois por cento dos entrevistados avaliaram a experiência no mestrado profissional a partir dos resultados produzidos. Eles perceberam o mestrado como uma experiência que produziu resultados tangiveis no desenvolvimento de habilidades, conhecimentos, mudanças de atitude e de postura, bem como na melhoria no exercício profissional. Avaliaram a experiência a partir das mudanças produzidas em suas vidas, tanto no âmbito pessoal quanto no profissional.

E3: "Eu classifico a minha formação como muito boa, apesar de não ser especificamente da área, porque adquiri muitos conhecimentos [...] acrescentou muito na minha formação original. Classifico muito bom para excelente."

E6: "Em termos de formação, achei que foi muito interessante, aprendi bastante. Os professores são muito bons [...] o mestrado atingiu minhas expectativas, pois pude aplicar muitas coisas em prática."

E5: "Hoje, quando alguém me procura para executar um serviço, sei exatamente como puxar dele informações necessárias para estabelecer um roteiro de ação [...] e saber equilibrar a expectativa dele. Apesar da empresa esperar uma receita, é aí que chega os conhecimentos aprendidos, você já mostra que existe um método e que você não é um fazedor de milagre, você não vai chegar e ser o xamã, o pajé."

E8: "A experiência foi fantástica em todos os sentidos, crescimento profissional, humano e como pessoa".

Está explícita nas declarações dos entrevistados a mobilização dos saberes aprendidos no mestrado em situações de trabalho.

A segunda categoria que emergiu dos depoimentos foi referente aos aspectos didático-pedagógicos, às condições de ensino que são externas ao aluno, que possibilitaram a construção de competências, sugerindo que a linearidade do modelo tradicional de ensinar e aprender foi rompida. Esses aspectos são confirmados nos fragmentos a seguir:

E1: "A maneira como os módulos foram conduzidos, o que aprendi com os colegas nas apresentações, tudo isso foi um aprendizado, somou para a minha competência e vai ser aplicado no meu dia a dia [...] 0 estudo de cases ajudou [...] Pude assimilar e trazer para dentro da minha vida profissional".

E1: "Consegui transpor os conteúdos para a minha prática". 
E8: “No princípio foi um pouco chocante acostumar com a metodologia. Foi uma forma inovadora de apresentar os conteúdos [...] No começo foi um pouco difícil encarar as formas de avaliação do mestrado, que são bem diferentes das da graduação. Na graduação a gente trabalha de uma maneira tradicional".

E2: “As disciplinas me ajudaram em uma reflexão [...] eu tinha alguns modelos na cabeça [...] eu era treinado para tomar decisões. Eu era muito prático".

E4: "Acabei descobrindo algumas habilidades que a gente não desenvolvia".

E9: "Eu acho que a metodologia foi boa, me deu conhecimentos muito amplos, melhorou os conhecimentos que tinha".

Os entrevistados relataram que a metodologia adotada permitiu reflexões sobre a relação entre as práticas profissionais e as teorias, e que os critérios avaliativos e as disciplinas foram responsáveis pelo sucesso alcançado.

As experiências relacionadas à pesquisa revelaram-se presentes em todas as entrevistas.

E1: “Fiz duas graduações e uma pós e em nenhuma delas tive que fazer artigo [...] tive uma dificuldade enorme para produzir um artigo".

E2: "Muitas habilidades que a gente desenvolve profissionalmente, elas carecem de uma visão mais aprofundada, principalmente voltada para a pesquisa [...] pude desenvolver, produzir artigos, fazer análises mais acadêmicas que práticas. Essa visão científica, de trabalho científico eu não tinha. Pude pegar a fundamentação teórica, pegar e ir para o campo da pesquisa, comparar os experimentos com a fundamentação teórica e, com base nisso, fazer conclusões, fazer novos insights e a partir daí, comprovar ou não".

A terceira categoria, com 18\% de frequência, englobou as restrições e dificuldades. Alguns entrevistados apontaram a questão da distribuição do tempo como uma das restrições e/ou dificuldades.

E9: "O tempo é muito pesado para uma pessoa trabalhar, fazer os créditos, fazer todas as leituras, fazer artigos e ainda avançar na dissertação".

E6: "A única observação é que nós trabalhamos, eu acho muito puxado, principalmente para quem leva a sério. Deveria alargar mais, a dissertação deveria ter mais tempo". 
É notória a dificuldade que os profissionais de mercado enfrentam ao serem exigidos artigos e trabalhos acadêmicos, tais como a dissertação. A lógica organizacional está muito mais direcionada à promoção de ações de rápido efeito, corrigindo questões pontuais, muitas das quais focadas nos efeitos e não nas causas. A relação positiva entre os esforços empreendidos versus a efetividade dos resultados, necessária tanto em um mestrado profissional quanto acadêmico, leva tempo a ser desenvolvida. Internalizar o novo ritmo exige aceitar uma nova forma de apreensão e registro das leituras a serem realizadas, exige disciplina espartana no uso do tempo escasso e foco no tema a ser investigado.

Uns apontaram dificuldades relacionadas à organização:

E9: “Eu acho que poderia ter sido melhor. Coisas que vamos percebendo. A última palestra deveria ter sido a primeira, a que falou sobre pesquisa, como seria a preparação, o tipo de dedicação necessária, a forma de leitura, então, algumas coisas que pudesse ser invertida".

E10: “Como o mestrado profissional é em gestão e estratégia, claro que não era para voltar em conceitos da graduação, mas eu acho que a discussão deveria ter sido mais voltada para estudos de casos empresariais e aprofundar essas discussões para o que acontece no âmbito das empresas. Muitos professores voltaram a conceitos que vi na graduação”.

Outros, dificuldades pessoais:

E1: "Tive dificuldade enorme para produzir artigo".

Ao longo de 24 meses, os alunos foram desafiados a produzir artigos, a elaborar planos de negócios e a analisar estratégias de empresas consolidadas no mercado. Apesar das dificuldades, reconheceram os conhecimentos sobre pesquisa e a produção científica daí resultantes como ganhos.

E2: “Meus artigos na área de tomada de decisão me ajudaram a fazer tomadas de decisão no meu trabalho, aqui dentro. Minha dissertação foi voltada para o meu trabalho".

E8: “Meus artigos foram voltados para a área onde atuo que é a nutrição. Apliquei na escola onde trabalho [...] Estou escrevendo sobre o local de 
trabalho e o estresse [...] Fiz um levantamento com meus alunos sobre a visão empreendedora e vou fazer uma parceria com o Sebrae para capacitar meus alunos a começarem seu próprio negócio".

E8: "Eu sempre quis escrever alguns livros dentro da minha área técnica, mas eu me senti incapaz de colocar no papel. Em virtude dessa massacrante produção de artigos que tivemos que fazer, estou louca para terminar o mestrado e começar a escrever um livro".

De acordo com Quellhas et al. (2005), os mestrados profissionais são direcionados para profissionais; por essa razão, os conteúdos devem enfatizar a aplicação na prática profissional e as atividades de pesquisa devem ser contempladas nas disciplinas e na dissertação.

Finalmente, na quarta categoria estão os sentimentos despertados. A experiência foi considerada como geradora de satisfação; expressões como "gostei muito“, "me deu confiança“, "aprendi bastante“، "foi uma experiência fantástica“, "valeu a pena“, "faria tudo outra vez" são comprovações dessa avaliação positiva do programa.

E1: "A vivência com outros profissionais e com os mestres me enriqueceu muito".

E12: "O mestrado foi muito bom para mim. Ele me deu novos horizontes, me abriu a cabeça [...] me deu a oportunidade de conversar e dialogar com colegas".

E9: "O mestrado foi fantástico. Eu adorei”.

\section{Mudanças percebidas}

A questão 3, 0 mestrado produziu mudanças em você? Fale-me sobre elas, produziu 77 categorias que foram reduzidas a um conjunto de quatro categorias mais amplas, a partir dos critérios de repetição e de diferenciação, conforme descrito na Tabela 4. 
Tabela 4. Categorização das respostas dos participantes à questão 3

\begin{tabular}{l|c|c}
\hline Categorias & Frequência & Porcentagem \\
\hline Âmbito Profissional & 24 & $36 \%$ \\
\hline Âmbito Pessoal & 22 & $33 \%$ \\
\hline Âmbito Científico & 13 & $19 \%$ \\
\hline Âmbito das Relações Interpessoais & 8 & $12 \%$ \\
\hline
\end{tabular}

A Tabela 5 apresenta o resumo geral da categorização das respostas, a partir das categorias e das unidades de análise, após a fusão das unidades de análise comuns em categorias mais amplas.

Tabela 5. Resumo geral da categorização das respostas dos participantes à questão 3

\begin{tabular}{l|l}
\hline Âmbito Profissional & $\begin{array}{l}\text { - maneira de realizar o trabalho; } \\
\text { - aplicação no trabalho; } \\
\text { - novos desafios; e }\end{array}$ \\
& - promoções e propostas. \\
\hline Âmbito Pessoal & - cognição; \\
& - valores; \\
& - prestígio; \\
& - tomada de decisão; \\
& - segurança; \\
& - postura; \\
& - autoestima; \\
& - pensar antes de agir; e \\
\hline Âmbito Científico
\end{tabular}

Segundo Zarifian (2001), um dos aspectos mais relevantes da utilização da lógica da competência é a capacidade que o profissional tem de tomar decisão e agir, substituindo a lógica do posto de trabalho pela lógica da competência. Ao assumir responsabilidades, ele se posiciona no campo das relações sociais, no âmbito da empresa, apresentando competência social, observável na sua capacidade de agir com autonomia, responsabilidade e no estabelecimento de relações interpessoais de troca, entendimento recíproco, compartilhando com os outros referenciais, motivos e objetivos comuns. 
A leitura da Tabela 5 permite inferir que o programa foi capaz de promover o desenvolvimento de competências. As declarações apontam para a aquisição de conhecimentos, habilidades e atitudes nos âmbitos profissional, pessoal, científico e interpessoal e habilidades relacionadas à gestão e estratégia.

\section{Mudanças no âmbito profissional}

Trinta e seis porcento das frequências recaíram sobre mudanças no plano profissional. Os entrevistados relataram ter adquirido saberes teóricos e procedimentais, aprimorando o saber-fazer de sua profissão. Foram capazes de realizar planejamento estratégico, gestão de recursos humanos com foco em resultados, usar de estratégias de marketing, usar de estratégias de negociação e implantar novas metodologias de trabalho, considerando a melhoria nos processos a partir de uma visão empreendedora.

Nas entrevistas, pode-se constatar que o planejamento do processo de formação propiciou espaços reflexivos sobre as grandes questões do mundo moderno. O programa favoreceu um processo contínuo earticulado de formação e desenvolvimento de conhecimentos, habilidades e atitudes, associando a modernidade técnica com saberes éticos.

Os fragmentos a seguir permitem comprovar que os entrevistados adquiriram competências que os tornaram capazes de saber agir e reagir com pertinência:

E3: "Fui chamado para trabalhar na Volks, optei por ficar na área de pesquisa e fui promovido."

E5: "Ganhos na carreira, em termos de mercado. Tive propostas de outras instituições, da Unimed, houve um fluxo de chamada de clientes."

E4: "Tive ganhos em termos de remuneração, passei a ganhar como mestre. Abriu novos campos. Hoje estou seguro para pegar novas áreas."

E5: "Hoje trabalho no Sebrae com núcleos associativistas. Foi quando terminei o mestrado que comecei, trabalho com núcleos de escolas, lan houses, agências de publicidade, padarias. A escola disse que teve um aumento de $30 \%$ do faturamento. Lan house e publicidade, 
posicionamento e visibilidade no mercado. Eles ainda não estão na fase de mensurar ganhos. Fizemos um evento, encontro sul fluminense de lan house, e o resultado foi que outros grupos de um município vizinho me procuraram para fazer um trabalho."

E6: "Estou participando de dois grupos de trabalho em minha empresa: planejamento estratégico e um de alta performance. A gente leva contribuições do que estudou, dos autores modernos."

E6: "Fiz um projeto de incorporação onde apliquei conhecimentos para o sucesso da incorporação. Precisavam de alguém para tocar a nova instituição, precisei aplicar conhecimentos de negociação, de planejamento estratégico [...] precisei gerenciar pessoas, insatisfações [...] as pessoas acreditaram em minha causa."

Os depoimentos evidenciaram que a proposta do mestrado profissional possibilitou aos entrevistados a aplicação, em um campo profissional definido, de conhecimentos e métodos científicos atualizados (GAZZOLA, 2003 apud PIQUET; LEAL; TERRA, 2005), a partir de uma visão horizontal dos saberes de gestão e estratégia e de reflexões interdisciplinares em busca do enfrentamento dos problemas concretos, utilizando, de forma direcionada, o conhecimento existente para equacionar tais problemas.

Os resultados são louváveis, porém é preciso cautela para comparar tais resultados com a qualificação média dos profissionais da região, não somente em termos formativos, como inclusive em níveis de desenvolvimento profissional. Esse é assunto para outra pesquisa. Como ganho para a proposta de um mestrado profissional, entretanto, a confirmação de que, mesmo com pouca experiência nos caminhos do que seria um mestrado profissional, o mestrado já buscava intuitivamente atender às demandas profissionais.

\section{Mudanças no âmbito pessoal}

As mudanças ocorridas no âmbito pessoal apontam para a teoria da identidade social de Tajfel. Segundo esse autor, a identidade social é decorrente da percepção de pertença a um grupo e de não pertença a outro. Ao comparar o seu grupo (in-group) com os demais grupos (out-groups), o indivíduo adquire distintividade positiva, fortalecendo sua autoestima e dos demais componentes do in-group (SENOS, 1997). 
As mudanças no âmbito pessoal foram responsáveis por 33\% das frequências, sendo essa a segunda categoria. Nela, foram agrupadas unidades de análise referentes a: valores, prestígio, cognição, tomada de decisão, segurança, postura, autoestima e pensar antes de agir.

Os fragmentos a seguir demonstram a distintividade positiva:

E9: “Pessoalmente mudou, mexeu até com os meus valores. 0 aluno que começou o mestrado saiu com uma visão mais abrangente [...] Passei a refletir sobre qualidade de vida e vou mudar minha vida pessoal e profissional."

E3: “Amadureci muito como cidadão, como pessoa [...] Passei a ter maior flexibilidade para negociar com as pessoas."

E12: “Hoje eu não tomo uma decisão tão brusca como a gente toma na empresa, de imediato. Penso mais na hora de tomar decisões, em função da bagagem que adquiri."

E5: "Justamente por ter estudado, aprofundado tudo, volta e meia empresas me pediam para fazer planejamento estratégico e eu não tinha confiança. Recusava com desculpas. Agora meto a cara e faço. Já tenho um planejamento estratégico encomendada para julho. A titularidade me dá um prestígio no mercado. Quando você mostra o seu currículo em uma empresa [...]"

E9: “Aconteceram mudanças em minha vida profissional e pessoal. Eu notei uma diferença do antes e do depois na minha postura em sala de aula e na minha postura como gerente. Reúno muitos gerentes para reunião, para discussão e houve comentários na sala com relação a percepção na mudança da forma de eu conduzir as reuniões com o grupo. Achei muito legal!"

E4: "Eu transferi a aprendizagem para os meus alunos e usei na consultoria e na prefeitura."

A experiência no mestrado produziu mudanças na forma de perceber o mundo e a si mesmo. Os conteúdos da maior parte das disciplinas recaíram sobre problemas sociais como fome, distribuição de rendas, corrupção, escassez de recursos, poluição, descaso e violência, apontando para a gestão com foco na responsabilidade social, comprometendo as organizações com a construção de uma cidadania corporativa. Apontaram para um novo paradigma gerencial, capaz de sustentar as práticas de gestão e estratégia das empresas não somente com os lucros, mas, sobretudo, em valores calcados em uma ética planetária, na cidadania e na responsabilidade social. 
E9: “Com relação a valores, conhecimentos, ai vou além da competência. Como falei a matéria da Nogueira foi reflexiva. Me levou a pensar em uma grande revolução onde você faz as coisas certas de maneira gradual [...] a questão da inclusão, do respeito ao meio ambiente."

A vivência no mestrado também produziu mudanças na identidade social de seus alunos, fato explicado pelos conceitos de categorização e comparação social. Os alunos perceberam que passaram a pertencer a um novo grupo, de que estavam filiados a um conjunto de pessoas que se diferenciam de outras por determinadas características, proporcionando sentimento de bem-estar, fortalecendo a autoestima.

E1: “Mudei muito [...] Eu senti um reconhecimento, aumentou minha autoestima, eu senti que passei a me respeitar mais, a reconhecer que eu tenho um potencial elevado, que é reconhecido pelos meus colegas, encontrei uma tribo que pensa de uma forma parecida com a minha."

Considerando que Boterf (2003) afirma que o potencial de um indivíduo está na crença que ele possui, delineando suas ações, o mestrado profissional produziu o desenvolvimento de uma identidade positiva. Contribuiu para que seus alunos passassem a sentir segurança em mobilizar seus conhecimentos no meio em que atuam. Um profissional seguro é capaz de assumir riscos, cujos resultados serão aceitos pelo grupo de pertença.

\section{Mudanças no âmbito científico}

Dezenove por cento das frequências recaíram na categoria âmbito científico. Os dados nos remetem a um dos objetivos do mestrado profissional, que é o de assegurar o aprofundamento de conhecimentos e técnicas de pesquisa científica ou profissional. Lopes Neto et al. (2005) esclarecem que os mestrados profissionais devem formar para o mundo profissional, a partir da imersão na pesquisa aplicada, proporcionando a formação científica e profissional necessária. 
Os fragmentos a seguir deixam claro essa competência adquirida.

E2: "Mudanças? Há sim, produzir artigos [...] pegar a fundamentação teórica, pegar e ir para o campo da pesquisa, comparar experimentos com a fundamentação teórica, com base nisso tirar conclusões, fazer novos insights e a partir daí comprovar ou não o que se está estudando."

E4: "Eu produzia muito material didático para sala de aula. Tenho um site meu, mas não focado em desenvolver pesquisa científica [...] apanhei para escrever artigos [...] escrevia para passar para os alunos, mas não para tornar público, em congresso, ou seja, produção de conhecimentos."

E11: "Eu não tinha nenhum contato com a parte científica. Não me interessava por trabalho científico. Eu não lia trabalho científico. Recebi uma premiação de monografia."

Segundo Zarifian (2001, p. 145), "na aprendizagem de competências não se pode desprezar a dimensão do conhecimento". Considerando que os saberes teóricos representam um dos pilares da competência e que são recursos que devem ser mobilizados para um agir com pertinência, as competências ancoradas no conhecimento científico possibilitaram aos entrevistados a vivência do saber transpor, ou seja, saber agir em múltiplas situações e propor soluções, saber distanciar-se, funcionar "em dupla direção", saber utilizar seus metaconhecimentos para modelizar, saber determinar e interpretar indicadores de contexto, saber criar as condições de transponibilidade com o auxílio de esquemas transferíveis. Possibilitaram, ainda, a vivência do saber-aprender e aprender a aprender, ou seja, saber tirar lições da experiência, saber descrever como se aprende, saber agir em circuito duplo de aprendizagem.

A titulação e as competências adquiridas proporcionaram sentimentos de segurança, de realização pessoal, de credibilidade, de identidade profissional, de reconhecer que o outro é portador de verdades e que por isso deve ser ouvido. Tendo em vista que a competência não está no posto de trabalho, mas no indivíduo, o desenvolvimento do fortalecimento da autoestima dos entrevistados sugere que eles estão aptos a assumir responsabilidades.

E7: “Um título de mestre te abre portas. Hoje um título de mestre da instituição X não é o mesmo que ser mestre de outra instituição Y. Isso, 
na minha vida profissional, teve grande resultado."

E5: "O mestrado me deu segurança para trabalhar e a certeza de que o que fazia estava certo.”

\section{Mudanças no âmbito das relações interpessoais}

Doze por cento das unidades de análise apresentaram mudanças no âmbito das relações interpessoais. Segundo Zarifian (2001), a lógica da competência está diretamente relacionada com o exercício da cidadania, do saber ser. Ela pressupõe o comunicar-se no interior de equipes de trabalho e entre ocupações diferentes; o entender os problemas e as obrigações dos outros, a interdependência e a complementaridade, o entender a si mesmo e avaliar sua própria ação sobre os outros para poder trabalhar em equipe, redes ou em projetos, a compartilhar normas mínimas de justiça.

Os fragmentos a seguir demonstram essa competência:

\footnotetext{
E1: "Adquiri habilidades, conhecimentos [... ] ao trabalhar em equipe." E4: "Estou aprendendo a trabalhar em uma equipe multidisciplinar, trabalhar em um ambiente novo e aceitar desafios."

E5: "Desenvolvi competências de relacionamento para a gente se relacionar com pessoas, ter postura diante das outras pessoas que você não é o melhor que ninguém."
}

Boterf (2003, p. 124) reforça que "as aptidões ou qualidades pessoais são os recursos mais dificeis de expressar e de descrever, no entanto, não devem ser negligenciados". A capacidade de escuta, as atitudes de acolhida, a capacidade de iniciativa e a tenacidade são capacidades cada vez mais requeridas nos ambiente profissionais. Essas capacidades são reconhecidas no saber agir, no saber relacionarse com as pessoas.

As mudanças apontadas sinalizam que o programa de mestrado profissional avaliado produziu ganhos sociais para os seus alunos. Segundo Sarsur (2007, p. 11), um ganho social equivale a um conjunto de aspectos que favorecem o desenvolvimento do trabalhador como ser humano, em sua dimensão mais ampliada: como pessoa, como 
profissional e como cidadão. De que não é somente o desenvolvimento do indivíduo que conta, mas a sua inserção na sociedade e os impactos que causam a partir de suas ações.

\section{Conclusões}

Os resultados sugerem que o principal motivo que levou os entrevistados a procurarem o mestrado foi a busca de conhecimentos capazes de serem aplicados em seu campo profissional. Apontam que os entrevistados aplicaram os conhecimentos em seus trabalhos, melhoraram o desempenho profissional, cresceram como pessoa em função das discussões oportunizadas pelas disciplinas e do relacionamento com colegas e professores.

A percepção sobre a falta de tempo foi o maior obstáculo vivido. Esse fato desafia os candidatos a mestrados profissionais a reverem suas agendas de trabalho, o uso do tempo e sugere aos mestrados profissionais a reavaliação, sobretudo, das melhores alternativas a serem utilizadas nas avaliações parciais das disciplinas, garantindo os niveis de qualidade dos cursos à altura dos padrões de cursos stricto sensu.

Além desse obstáculo, alguns entrevistados salientaram que, embora todos os docentes estivessem dotados com a mais alta qualificação em termos de titulação e de conhecimentos, boa parte deles possuía pouca experiência profissional, o que sugere o estreitamento das relações entre os mestrados profissionais e os setores profissionais, por meio de projetos de pesquisa.

Por fim, os entrevistados demonstraram ter adquirido ganhos na carreira, ganhos pessoais e ganhos científicos. O mestrado contribuiu para retirá-los da sensação do conforto dos saberes profissionais que já possuíam, tomando consciência de novos saberes, movendo-os para diante, emancipando-os, abrindo caminho para a maturidade e para a autonomia profissional.

Essa mudança paradigmática da Capes, ao desenvolver uma nova proposta de formação no campo da pós-graduação, incita 
novos estudos e deve ser conduzida com grande seriedade, porque os mestrados profissionais representam a possibilidade de o Brasil desenvolver pesquisas em suas próprias empresas, contrariando a tendência homogeneizante de implantação de cases de sucesso de nações dominantes, resistindo à adoção de modelos internacionais, abrindo espaço para o fortalecimento nacional a partir da criação de referencial teórico brasileiro.

\section{Referências bibliográficas}

APCN. Mestrado Profissional2005. Revista Brasileira dePós-Graduação, v. 2, n. 4, p. 162-165, jul. 2005. Disponivel em: <http://www2.capes. gov.br/rbpg/images/stories/downloads/RBPG/vol.2_4_jul2005_/ Documentos_Artigo8_n4.pdf >. Acesso em: 20 jan. 2008.

BARDIN, L. Análise de conteúdo. Lisboa: Edições 70, 1995.

BARROS, E. C. et al. O debate sobre o mestrado profissional na Capes: trajetória e definições. Revista Brasileira de Pós-Graduação, v. 2, n. 4, p. 124-138, jul. 2005. Disponivel em:

<http://www2.capes.gov.br/rbpg/images/stories/downloads/ RBPG/vol.2_4_jul2005_/Documentos_Artigo1_n4.pdf >. Acesso em: 20 jan. 2008.

BITENCOURT, C. C. A gestão de competências gerenciais. A contribuição da aprendizagem organizacional. 2001. Tese (Doutorado em Administração) - Programa de Pós-Graduação em Administração, Universidade Federal do Rio Grande do Sul, Porto Alegre.

BOTERF, G. L. Desenvolvendo a competência dos profissionais. Porto Alegre: Artmed, 2003.

BRASIL. Ministério da Educação e Cultura. Parecer n ${ }^{\circ} 977$ CES, de 03 de dezembro de 1965.

Capes. Portaria $\mathbf{n}^{\circ} \mathbf{8 0 / 9 8}$ de 16 de dezembro de 1998. 
Capes. Portaria Normativa $\mathbf{n}^{\circ} \mathbf{1 7}$ de 28 de dezembro de 2009.

CAMPOS, J. A. Cenário Balanceado: painel de indicadores para a gestão estratégica dos negócios. São Paulo: Aquariana, 1998.

DELORS, J. et al. Educação um tesouro a descobrir. São Paulo: Cortez Editora/UNESCO/MEC, 1996.

FICHER, T. Mestrado profissional como prática acadêmica. Revista Brasileira de Pós-Graduação, v. 2, n. 4, p. 24-29, jul. 2005. Disponível em: <http://www2.capes.gov.br/rbpg/images/stories/downloads/ RBPG/vol.2_4_jul2005_/Debates_Artigo3_n4.pdf>. Acesso em: 20 jan. 2008.

GAZZOLA, 2003 apud PIQUET, R.; LEAL, J. A. A.; TERRA, D. C. T. Mestrado profissional: proposta polêmica no Sistema Brasileiro de Pós-Graduação - o caso do planejamento regional e urbano. Revista Brasileira de PósGraduação, v. 2, n. 4, p. 30-37, jul. 2005. Disponível em: < http://www2. capes.gov.br/rbpg/images/stories/downloads/RBPG/vol.2_4_ jul2005_/Debates_Artigo4_n4.pdf>. Acesso em: 20 jan. 2008.

LOPES NETO, S. J. et al. Mestrado no Brasil - a situação e uma nova perspectiva. Revista Brasileira de Pós-Graduação, v. 2, n. 4, p. 139-144, jul. 2005. Disponível em: <http://www2.capes.gov.br/rbpg/images/ stories/downloads/RBPG/vol.2_4_jul2005_/Documentos_Artigo2_ n4.pdf>. Acesso em: 20 jan. 2008.

MELO, K. V. A.; OLIVEIRA, R. R. Origens e desenvolvimento institucional de um mestrado profissional. Revista Brasileira de Pós-Graduação, v. 2, n. 4, p. 105-123, jul. 2005. Disponivel em: <http://www2.capes. gov.br/rbpg/images/stories/downloads/RBPG/vol.2_4_jul2005_/ Estudos_Artigo4_n4.pdf>. Acesso em: 20 jan. 2008.

MOURA CASTRO, C. A hora do mestrado profissional. Revista Brasileira de Pós-Graduação, v. 2, n. 4, p. 16-23, jul. 2005. Disponível em: <http:// www2.capes.gov.br/rbpg/images/stories/downloads/RBPG/ vol.2_4_jul2005_/Debates_Artigo2_n4.pdf>. Acesso em: 20 jan. 2008. 
QUELHAS, O. L. G. et al. O mestrado profissional no contexto do sistema de pós-graduação brasileiro. Revista Brasileira de Pós-Graduação, v. 2, n. 4, p. 87-104, jul. 2005. Disponivel em: <http://www2.capes.gov.br/ rbpg/images/stories/downloads/RBPG/vol.2_4_jul2005_/Estudos_ Artigo3_n4.pdf >. Acesso em: 20 jan. 2008.

RIBEIRO, R. J. O mestrado profissional na política atual da CAPES. Revista Brasileira de Pós-Graduação, v. 2, n. 4, p. 8-15, jul. 2005. Disponível em: <http://www2.capes.gov.br/rbpg/images/stories/downloads/ RBPG/vol.2_4_jul2005_/Debates_Artigo1_n4.pdf >. Acesso em: 20 jan. 2008.

SARSUR, A. M. Gestão por competências: a percepção de ganho social do trabalhador. 2007. Tese (Doutorado em Administração) - Departamento de Administração, Faculdade de Economia, Administração e Contabilidade, Universidade de São Paulo, São Paulo.

SENOS, J. Identidade social, autoestima e resultados escolares. Análise pedagógica, v. 1, 15, p. 123-137, 1997.

SILVEIRA, V. O.; SOUZA PINTO, F. C. Reflexões necessárias sobre o mestrado profissional. Revista Brasileira de Pós-Graduação, v. 2, n. 4, p. 38-47, jul. 2005. Disponivel em: <http://www2.capes.gov.br/ rbpg/images/stories/downloads/RBPG/vol.2_4_jul2005_/Debates_ Artigo5_n4.pdf >. Acesso em: 20 jan. 2008.

TILLICH, P. A Coragem de Ser. 2. ed. Rio de Janeiro: Paz e Terra, 1972.

TURATO, E. R. Tratado da metodologia da pesquisa clínico-qualitativa: construção teórico-epistemológica nas áreas da saúde e humanas. Petrópolis, RJ: Vozes, 2003.

VILLAS BOAS, A. A. et al. Em busca do perfil do egresso do profissional de administração- diagnóstico do programa de mestrado profissional em gestão e estratégia em negócios - PPGEN da UFRRJ. Projeto e subprojeto fase II. Rio de Janeiro: Seropédica, jun. 2006.

ZARIFIAN, P. Objetivo competência. Por uma nova lógica. São Paulo: Atlas, 2001. 


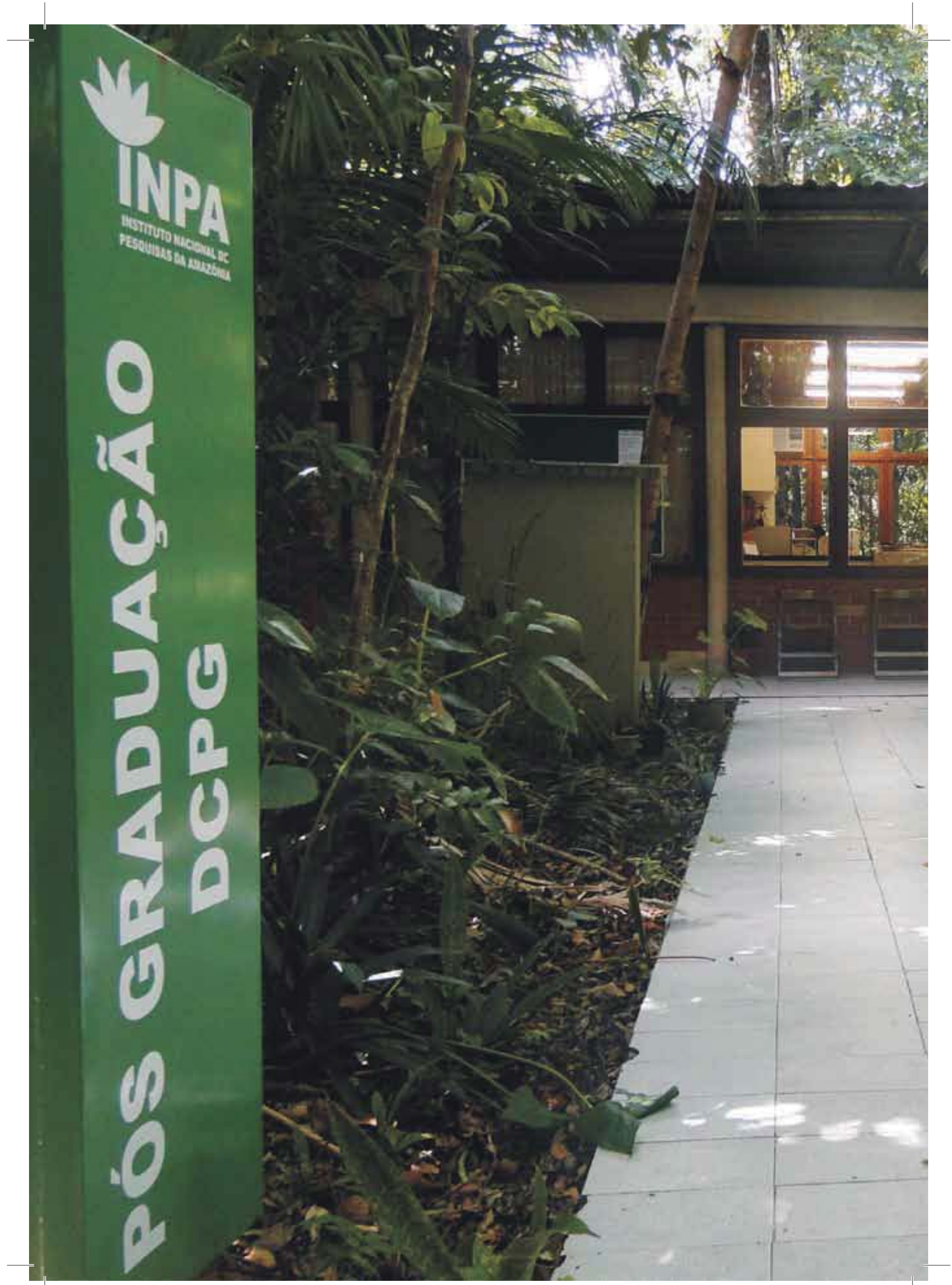


52

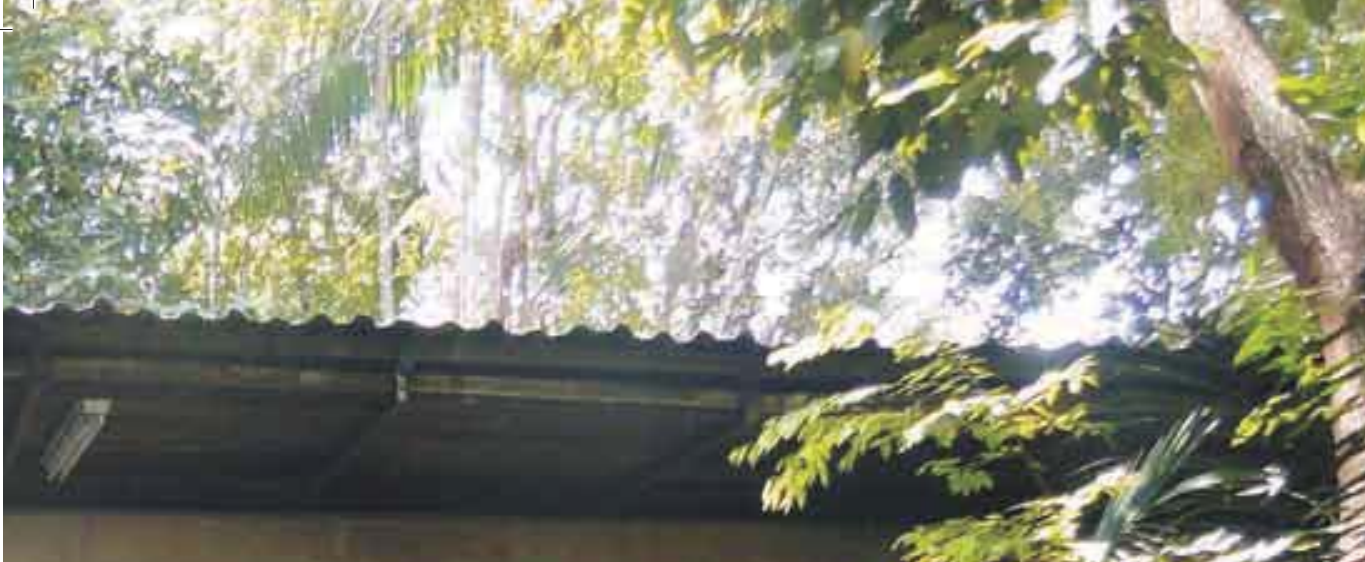

3
2

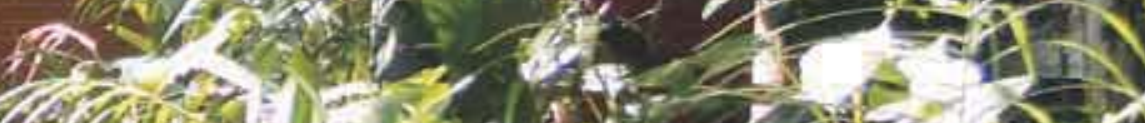

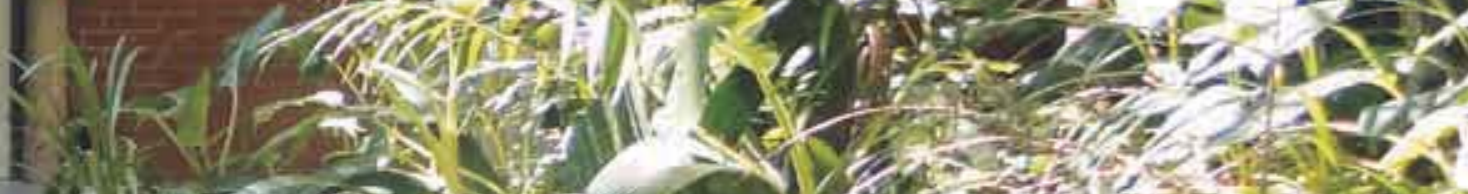

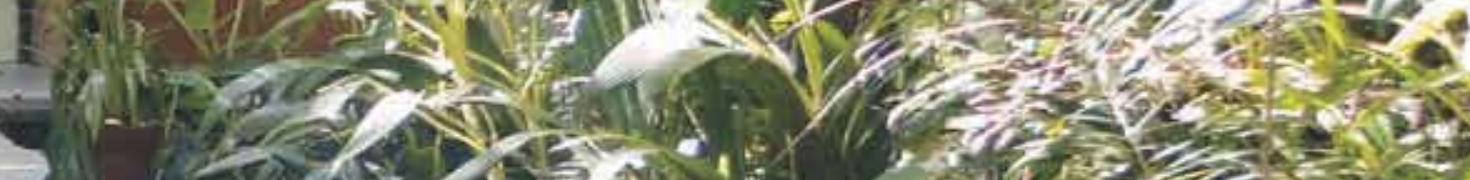
21 (2)

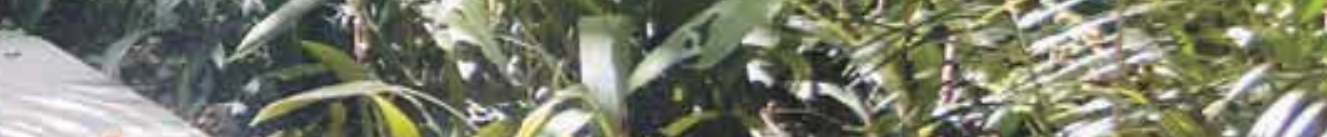

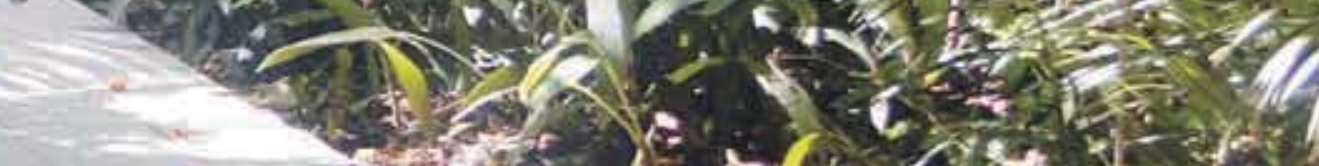

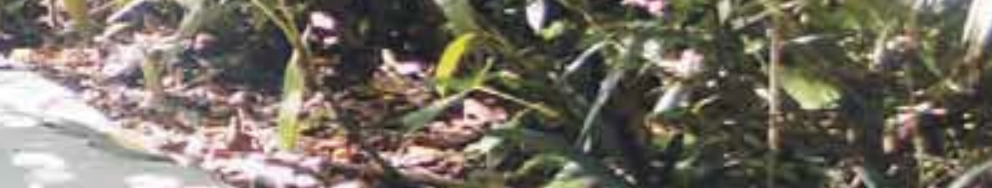

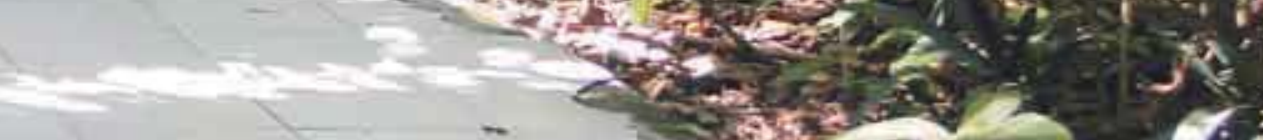
- visy

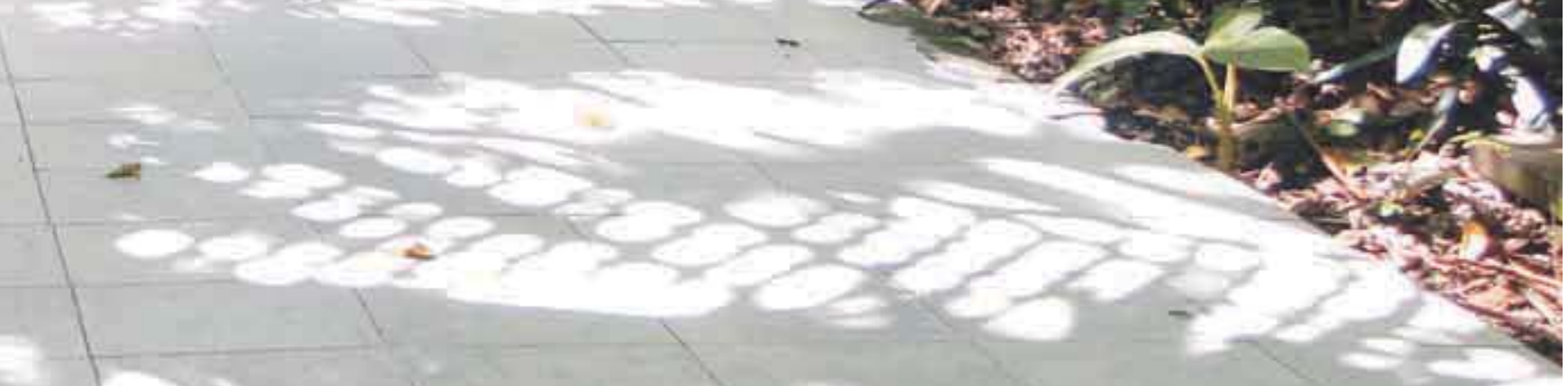

Instituto Nacional de Pesquisas da Amazônia (Inpa/MCTI), prédio da Secretaria dos Programas de Pós-Graduação. Foto de Daniel Jordano, Inpa. 